\title{
Cijevni milireaktori izrađeni aditivnom proizvodnjom
}

\author{
M. Lukić,* T. Rahelić i D. Vrsaljko
}

Sveučilište u Zagrebu, Fakultet kemijskog inženjerstva i tehnologije,

Marulićev trg 19, 10000 Zagreb

\begin{abstract}
Sažetak
Aditivnom proizvodnjom moguće je izraditi proizvode složene geometrije koje konvencionalnim tehnikama poput tokarenja i glodanja nije moguće izraditi. Primjenom proizvodnje rastaljenim filamentom - FFF (engl. Fused Filament Fabrication) i stereolitografije - SLA (engl. Stereolithography) moguće je izraditi složene unutarnje strukture, tankostijene dijelove (milikanale) kao i dijelove unutar dijelova (pregrade).

Cilj ovoga rada bio je ispitati mogućnosti 3D ispisa na uređajima Zortrax M200 (FFF) i Formlabs Form 2 (SLA) u svrhu izrade funkcionalnih milireaktora s unutarnjim pregradama.

Kako bi se istražio utjecaj dimenzija milikanala na reakciju, ali i demonstrirala funkcionalnost cijelog sustava, u milireaktorima s pregradama je provedena sinteza FAME-a (engl. Fatty Acid Methyl Esters) transesterifikacijom suncokretovog ulja pomoću metanola uz dodatak baznog katalizatora $\mathrm{KOH}$.
\end{abstract}

\section{Ključne riječi}

Milireaktor s unutarnjim pregradama, aditivna proizvodnja, 3D ispis,

proizvodnja rastaljenim filamentom, stereolitografija, sinteza FAME

\section{Uvod}

Aditivna proizvodnja, AM (engl. Additive Manufacturing), u široj javnosti poznatija pod nazivom tehnologija 3D ispisa spada u proizvodno strojarstvo i bavi se izradbom predmeta nanošenjem čestica u slojevima (sloj po sloj). Aditivnom proizvodnjom moguće je izraditi proizvode složene geometrije koje konvencionalnim tehnikama nije moguće izraditi (npr. glodanje i tokarenje). Složeni 3D proces izgradnje pojednostavljuje se pretvaranjem u 2D slojeve koji se izrađuju i slažu zajedno, nakon čega tvore 3D tvorevinu. ${ }^{1}$

Prototip proizvoda izrađuje se računalom potpomognutim oblikovanjem (engl. Computer Aided Design) u nekom od 3D programa (Catia, Solidworks, FreeCAD, SketchUp i dr.) te se izrađeni 3D model sprema u STL datoteku (engl. Standard Tessellation Language), koja model prikazuje kao mrežu povezanih trokuta i prebacuje se na 3D pisač.

Aditivna proizvodnja može se podijeliti, s obzirom na vrstu materijala, na one koje se koriste kapljevitim materijalima (npr. epoksidne i akrilne smole), krutim (npr. polipropilen i akrilonitril/butadien/stiren) i materijalima u obliku praha (npr. poliamid). ${ }^{2}$

lako u samom oblikovanju proizvoda pomoću CAD softvera nema ograničenja, granice postavljaju dostupni materijali od kojih se predmeti izrađuju, tj. njihova fizikalna i kemijska svojstva.

$\mathrm{U}$ ovom radu proizvedeni su milireaktori s pregradama aditivnom proizvodnjom pomoću tehnologije proizvodnje rastaljenim filamentom, FFF i stereolitografije, SLA.

\subsection{Proizvodnja rastaljenim filamentom}

Osnovni princip FFF-a je da se filament polimernog materijala gura u vruću mlaznicu iz koje izlazi tanka nit polimerne taljevine. Tvorevina se izrađuje tako da se mlaznica pomiče u x-y ravnini stvarajući jedan sloj te po završetku sloja mlaznica se diže, ili podloga spušta te se izrađuje sljedeći sloj. Rezolucija slojeva kod stolnih varijanti pisača je u rasponu od $0,05 \mathrm{~mm}$ do $0,3 \mathrm{~mm}$. Komercijalno su dostupni filamenti promjera $1,75 \mathrm{~mm}$ ili

\footnotetext{
*Autor za dopisivanje: Marija Lukić, mag. ing. cheming.,
} e-pošta:mlukic@fkit.hr 
$3 \mathrm{~mm}$ od raznovrsnih materijala i boja. Najčešće upotrijebljeni filamenti su od polimera akrilonitril/butadien/stirena (ABS) i polilaktida (PLA), a također su dostupni i poli(etilen-tereftalat) obogaćen glikolom (PETG), polikarbonat (PC), poli(metil-metakrilat) (PMMA), poliolefini (PE-LD, PE-HD, PP), polistiren visoke žilavosti (HIPS) i poli(vinil alkohol) (PVA).

U programu koji računalni model dijeli u pojedinačne slojeve i pokrete mlaznice, izrada modela dijeli se na vanjsku i unutarnju stjenku, ispunu te na početne i završne slojeve, koji zatvaraju objekt s gornje i donje strane. Također, moguće je regulirati količinu ispune tiskanog predmeta od 0 do $100 \%$ (vrijeme za izradu proizvoda i potrošnja materijala ovise o tom faktoru). U slučaju izrade cijevnih milireaktora bila je potrebna $100 \%$-tna ispuna radi sprječavanja propuštanja kapljevine između slojeva.

\subsection{Stereolitografija}

Stereolitografija je tehnologija koja radi na principu da se pomoću lasera očvršćivanjem fotoosjetljive smole dobiva jedan sloj. Stereolitografijom se dobivaju predmeti s glađom površinom i finijim detaljima u odnosu na predmetne izrađene proizvodnjom rastaljenim polimerom. Posuda pisača napunjena je fotoosjetljivom smolom i obložena zaštitnom komorom koja sprječava prodiranje UV zračenja iz prostorije. Laserom se crtaju konture u x-y smjeru čineći jedan sloj. Nakon završetka jednog sloja platforma $\mathrm{s}$ djelomično izrađenim predmetom diže se $u$ smjeru z osi za visinu debljine sloja. ${ }^{3}$ Rezolucija pisača Formlabs Form 2 je 0,025 mm stoga je pogodna za izradu milireaktora jer stvara puni predmet s visokom preciznošću koji ne propušta između slojeva kao što to može biti slučaj kod proizvodnje rastaljenim filamentom. Navedena svojstva omogućuju odabir tehnologije SLA kao dobar izbor za razvoj i izradu prototipova reaktora. Nedostatak je mali izbor dostupnih materijala zbog uskog raspona fotopolimera koji očvršćuju pod UV svjetlom, a bazirani su na akrilatima, epoksidima i uretanima. ${ }^{4}$

\subsection{Dobivanje FAME}

Esteri masnih kiselina dobivaju se reakcijom transesterifikacije (slika 1) koja uključuje reakciju triglicerida, glavnog sastojka biljnog ulja ili životinjske masti, i nižih alkohola (metanol ili etanol) uz prisutnost katalizatora. Kao produkt nastaje odgovarajući ester masne kiseline odnosno FAME ili FAEE (engl. fatty acid ethyl esters) ako je polazna sirovina etanol i glicerol koji su međusobno nemješljivi. Metanol i etanol najčešće su rabljeni alkoholi zbog svoje reaktivnosti i niske cijene. ${ }^{5}$

Jedna molekula triglicerida reagira s tri molekule alkohola te nastaju tri molekule monoalkiliranog estera (FAME) te jedna molekula glicerola (slika 1). Reakcija se odvija postupno u tri stupnja koji rezultiraju digliceridom i monogliceridom kao međuproduktima. Općenito, transesterifikacija se provodi uz lužnate ili kisele katalizatore. Za upotrebu lužnatih katalizatora, sirovine trebaju biti bez vode (vlage) te udio slobodnih masnih kiselina u ulju treba biti manji od 0,5\%. Kod većih udjela slobodnih masnih kiselina i ukoliko ima vode u sirovini, preferira se kiselo katalizirana transesterifikacija. Najčešći lužnati katalizatori su kalijev i natrijev hidroksid, dok se za kisele katalizatore upotrebljavaju sumporna, klorovodična i fosforna kiselina. Lužnato katalizirana reakcija bazirana na metanolu standardno se provodi pri temperaturi $T=60{ }^{\circ} \mathrm{C}$ i molarnom omjeru metanol:ulje $6: 1$ za transesterifikaciju. ${ }^{5}$ Najjednostavniji način proizvodnje FAME je u kotlastom reaktoru s miješanjem, a nemješljivost ulja i alkohola ograničava brzinu reakcije te reakcija uglavnom traje nekoliko sati. ${ }^{6}$ Ubrzanje reakcije postiže se povećanjem međufazne površine uz pomoć ultrazvuka, ${ }^{7}$ mikrovalnim grijanjem, ${ }^{8}$ ili superkritičnim uvjetima. ${ }^{9}$ Jedan od načina povećanja međufazne površine između ulja i alkohola je upotreba mikroreaktora koji su pokazali bržu konverziju u odnosu na konvencionalne kotlaste reaktore, a pogodni su za brzo traženje optimalnih reakcijskih uvjeta poput temperature, omjera metanola/ulja i udjela katalizatora uz malu potrošnju reaktanata zbog malih reakcijskih volumena. ${ }^{10,11}$

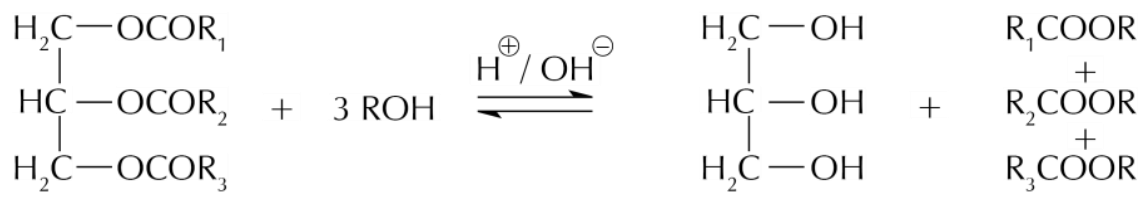

Slika 1 - Dobivanje FAME - transesterifikacija triglicerida alkoholom

Fig. 1 - FAME synthesis - transesterification of triglyceride with alcohol 
Tablica 1 - Karakteristične skupine za ulje i FAME ${ }^{13}$

Table 1 - Characteristic groups for oil and FAME ${ }^{13}$

\begin{tabular}{|c|c|c|c|}
\hline $\begin{array}{l}\text { Maksimum } \\
\text { apsorpcije } / \mathrm{cm}^{-1}\end{array}$ & Skupina & $\begin{array}{c}\text { Ulje } \\
\text { (trigliceridi) }\end{array}$ & $\begin{array}{c}\text { FAME } \\
\text { (ester masne kiseline) }\end{array}$ \\
\hline 1445 & $\mathrm{CH}_{3}$ asimetrično savijanje & - & + \\
\hline $1370-1400$ & $\begin{array}{l}\mathrm{OCH}_{2} \text { grupa u glicerolnim } \\
\text { skupinama glicerida }\end{array}$ & + & - \\
\hline $1238-1248$ & $\mathrm{O}-\mathrm{H}$ deformacija & + & + \\
\hline 1200 & $\mathrm{OCH}_{3}$ rastezanje & - & + \\
\hline 1170 & $\begin{array}{c}\mathrm{C}-\mathrm{O}-\mathrm{C} \text { rastezanje, } \mathrm{C}-\mathrm{C} \\
\text { rastezanje }\end{array}$ & + & + \\
\hline 1100 & $\begin{array}{c}\mathrm{O}-\mathrm{CH}_{2}-\mathrm{C} \text { asimetrično } \\
\text { savijanje }\end{array}$ & + & - \\
\hline
\end{tabular}

\subsection{Analiza FAME infracrvenom spektroskopijom}

Spektroskopske metode poput FTIR-a postaju zanimljive zato što je analiza brza, nedestruktivna i ne zahtijeva posebnu pripremu uzorka kao što je to kod plinske kromatografije, GC (engl. gas chromatography), tehnike koja se najčešće primjenjuje za analizu FAME. ${ }^{12}$ Također nije potrebno primjenjivati unutarnje standarde kao što je to kod GC-a ili HPLC-a. ${ }^{13}$ Pripremanjem smjesa poznatih sastava FAME i ulja, Siatis $i$ sur. ${ }^{7}$ razvili su kvantitativne analitičke metode za određivanje udjela FAME u reakcijskoj smjesi. U tablici 1 navedene su karakteristične skupine koje uzrokuju razlike u spektrima između FAME i ulja te pomoću njih, tj. promjenom u apsorpciji može se pratiti napredovanje reakcije. Također, FTIR tehnika pogodna je za on-line praćenje reakcije. ${ }^{14}$

\section{Eksperimentalni dio}

\subsection{Materijali upotrijebljeni za aditivnu proizvodnju}

U ovom radu upotrijebljeni su sljedeći materijali za proizvodnju rastaljenim filamentom:

- Z-ULTRAT ivory, Zortrax, Poljska; (1,75 mm), na osnovi ABS-a

- PMMA, Filament PM, Češka; (1,75 mm), na osnovi PMMA

Fotoosjetljiva smola upotrijebljena za izradu stereolitografijom:

- Clear Resin V2 (GPCL02), Formlabs, SAD, na osnovi PA

\subsection{Kemikalije upotrijebljene za sintezu FAME}

U ovom radu upotrijebljene su sljedeće kemikalije:

- suncokretovo jestivo ulje, proizvedeno u EU-u

- metanol 99,9 \% p.a., Carlo Erba reagents, Francuska

- klorovodična kiselina 36,5 \%, Kemika, Hrvatska

- kalijev hidroksid p.a., T.T.T. d. o. o., Hrvatska

\subsection{Sinteza FAME u kotlastom reaktoru}

Sinteza FAME provedena je u kotlastom reaktoru opremljenom magnetnom miješalicom, uljnom kupelji i hladilom za povrat para metanola. Reakcija se provodila pri temperaturi $T=60^{\circ} \mathrm{C}$ u trajanju od tri sata. Za sintezu FAME upotrijebljen je maseni udio katalizatora od $1 \%$, a količina metanola odabrana je tako da okvirno odgovara molarnom omjeru metanol : ulje $6: 1$. Broj je približan, jer nije izmjerena točna srednja molekulska masa ulja nego su primijenjeni literaturni podatci za molarnu masu suncokretova ulja $M=876 \mathrm{~g} \mathrm{~mol}^{-1} .^{15}$ Prije provedbe reakcije u 24,9 ml metanola otopljeno je 0,900 g kalijeva hidroksida koji služi kao katalizator, pripravljena otopina je korištena svježa. Potom je u kotlasti reaktor dodano 90,0 g suncokretova ulja i metanol s otopljenim kalijevim hidroksidom. Oba reaktanta prethodno su zagrijana na temperaturu $T=60^{\circ} \mathrm{C}$. Po završetku reakcije reakcijska smjesa prebačena je u lijevak za odjeljivanje te ostavljena $24 \mathrm{~h}$ da se sirovi FAME odvoji od glicerolske faze s neizreagiranim metanolom i kalijevim hidroksidom. Kako bi se dobio čisti FAME i kako bi se neutralizirao zaostali kalijev hidroksid, $20 \mathrm{ml}$ dobivenog sirovog FAME isprano je protresanjem u tikvici sa $60 \mathrm{ml}$ klorovodične kiseline koncentracije $c(\mathrm{HCl})=0,5 \mathrm{moll}^{-1}$. FAME je odvojen od vodene faze te je potom ispran po dva puta sa $60 \mathrm{ml}$ destilirane vode. Tako dobiveni FAME smatran je čistim te je kasnije služio za pripravu otopina za dobivanje baždarnog dijagrama.

\subsection{Sinteza FAME u milireaktoru s pregradama}

Pomoću klipnih pumpi u reaktor su dodavani reaktanti metanol (s otopljenim kalijevim hidroksidom) i suncokretovo ulje. Reakcija se provodila pri temperaturi $T=60{ }^{\circ} \mathrm{C}$. Na samom izlazu iz milikanala (slika 2) spojena je silikonska cjevčica koja produkt dovodi izravno do vijale u koju je prethodno dodana vodena otopina klorovodične kiseline $c(\mathrm{HCl})=0,5 \mathrm{~mol} \mathrm{I}^{-1}$ što omogućuje zaustavljanje reakcije. 
Za potrebe rada izrađene su klipne pumpe temeljene na platformi Arduino. ${ }^{16}$ Pumpe su upravljane preko računalnog sučelja napisanog u Pythonu. Pomoću računalnog sučelja zadan je željeni protok reaktanata te promjer upotrijebljene šprice.

Prije početka reakcije, svježe je pripremljena otopina kalijeva hidroksida u metanolu, $\gamma(\mathrm{KOH})=36,12 \mathrm{gl}^{-1}$. Bez obzira na ukupni protok držan je jednak volumni omjer ulja i metanola od $4,06: 1$, što uz upotrijebljenu koncentraciju kalijeva hidroksida u metanolu odgovara $1 \%$ katalizatora prema masi ulja.
Sinteza je provedena u četiri reaktora s pregradama. Tri reaktora imala su promjer cijevi $2,5 \mathrm{~mm}$ i unutarnje pregrade valjkastog oblika $1 \mathrm{~mm}$, ali su različite duljine, a time i vremena zadržavanja. Napravljen je i jedan reaktor promjera cijevi $1,2 \mathrm{~mm}$ i unutarnje pregrade valjkastog oblika $0,5 \mathrm{~mm}$. Pojam mikroreaktora u osnovi se veže s dimenzijama njegove osnovne strukturne jedinice mikrokanala (tipičnih dimenzija u rasponu $10 \mu \mathrm{m}-500 \mu \mathrm{m}),{ }^{17}$ stoga reaktori napravljeni aditivnom proizvodnjom (tablica 2) spadaju u skupinu milireaktora.

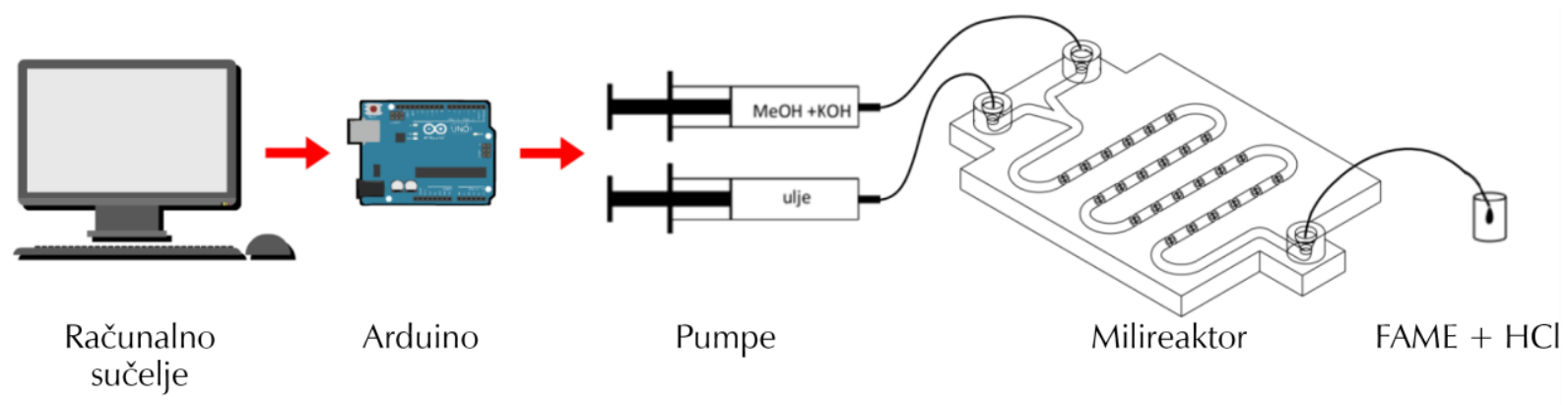

a)

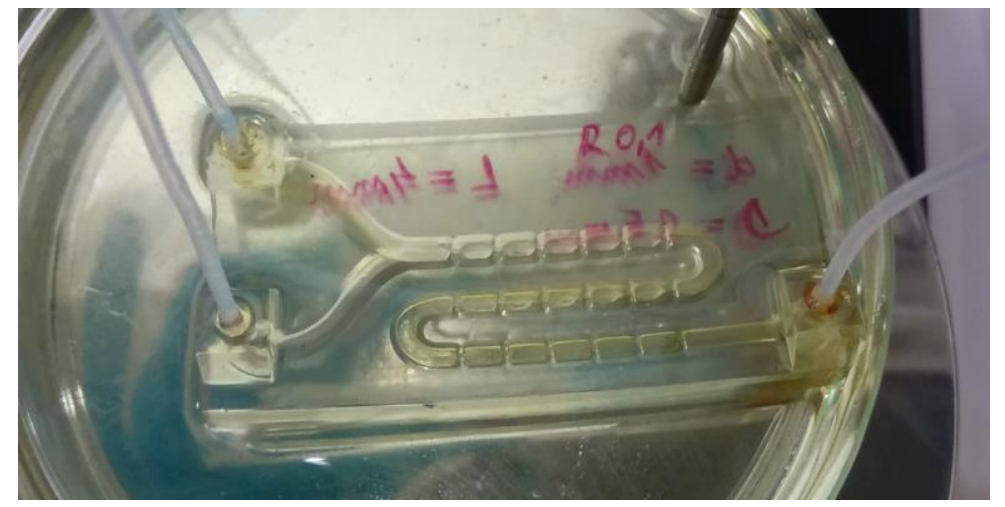

b)

Slika 2 - a) Shematski prikaz reakcijskog sustava sinteze FAME u milireaktoru s pregradama; sastoji se od klipnih pumpi, milireaktora u uljnoj kupelji te skupljanja produkta u vijalu, b) fotografija reaktora u uljnoj kupelji tijekom odvijanja reakcije

Fig. 2 - a) Schematic presentation of the reaction system of FAME synthesis in the millireactor with baffles; consists of piston pumps, millireactor in oil bath, and collection of the product in the vial, b) photography of reactor in oil bath during synthesis

\subsection{FTIR analiza}

Mjerenja su provedena na infracrvenom spektrofotometru $\mathrm{s}$ Fourierovom transformacijom signala PerkinElmer Spectrum One opremljenim s ATR dodatkom. Uzorci su snimani u području od 4000 do $600 \mathrm{~cm}^{-1}$ rezolucijom od $4 \mathrm{~cm}^{-1}$. Kako bi se povećao odnos signala prema šumu, svaki uzorak snimljen je četiri puta, a u grafovima je prikazana njihova srednja vrijednost. Mjerenje je provedeno tako da je kap uzorka prenesena staklenim štapićem na ATR kristal. Zajedno sa serijom uzoraka kojima je određena konverzija snimljeni su i spektri čistog FAME i čistog suncokretova ulja koji su služili kao referencije.

Za određivanje konverzije FTIR-om odnosno mjerenja udjela FAME u uzorcima, pripremljene su baždarne otopine različitih koncentracija suncokretova ulja i iz njega 
dobivenog FAME. Snimljeni su infracrveni spektri uzoraka te su iz dobivenih spektrograma određena područja gdje dolazi do odstupanja u spektrima tj. visini signala ovisno o koncentraciji FAME i ulja.

\section{Rezultati i rasprava}

\subsection{Reakcija u kotlastom reaktoru}

$\mathrm{U}$ svrhu ispitivanja kemijske reakcije provedena je sinteza u kotlastom reaktoru i snimljene su baždarne krivulje za određivanje udjela FAME. Na slici 3 je prikazan infracrveni spektar suncokretova ulja (sun. ulje) i iz njega dobivenog FAME.

Na slici 4 prikazan je dio FTIR spektra dobiven uzimanjem uzorka u vijalu u različitim vremenskim intervalima. Oko pedesete minute nastaje FAME te reakcija traje još minimalno do 120. minute. Snimanjem spektara uočljivo je da nema većih odstupanja u FTIR spektrima uzoraka dobivenih reakcijom nakon $120 \mathrm{~min}, 180 \mathrm{~min}$ te $3 \mathrm{~h}+$ $24 \mathrm{~h}$.

Na slici 5 nalaze se dijelovi FTIR spektara baždarnih smjesa za određivanje udjela FAME, napravljene razrjeđenjem modelnog FAME iz kotlastog reaktora dobivenog pri
$3 \mathrm{~h}+24 \mathrm{~h} \quad(w($ FAME $)=100 \%) . \quad$ Vidljivo je nekoliko karakterističnih vrpci s vrhovima na $1436 \mathrm{~cm}^{-1}$, $1196 \mathrm{~cm}^{-1}, 1099 \mathrm{~cm}^{-1}$ po kojima se razlikuju suncokretovo ulje i iz njega dobiven FAME. Razlika u spektrima u području oko $1099 \mathrm{~cm}^{-1}$ odgovaraju vibraciji skupine $\mathrm{O}-\mathrm{CH}_{2}-\mathrm{C}$ koja je karakteristična za ulje, tako da $\mathrm{s}$ povećanjem udjela FAME raste transmisija u tom području. Spektri se znatno razlikuju i u području oko $1196 \mathrm{~cm}^{-1}$ što odgovara rastezanju metilne skupine $\mathrm{O}-\mathrm{CH}_{3} .{ }^{7} \mathrm{Ta}$ je skupina karakteristična za FAME, te povećanjem udjela FAME na tom mjestu opada transmisija. Također je vidljiva značajna razlika na području oko $1436 \mathrm{~cm}^{-1}$ što odgovara asimetričnom savijanju skupine $-\mathrm{CH}_{3}{ }^{14}$

Za svaku od tih skupina nacrtana je baždarna krivulja (slika 6) ovisnosti transmisije o koncentraciji FAME kako bi se odredilo područje u kojem je najbolje pratiti reakciju tj. na kojem području transmisija ostvaruje najsnažniji i najlinearniji odziv. Utvrđeno je da signali u svim područjima pokazuju dobar linearni odziv ovisnosti masenog udjela FAME jer je kod svih vrijednost $R^{2}$ veća od 0,9952. Za praćenje konverzije odabrana je vrijednost transmisije na vrhu od $1099 \mathrm{~cm}^{-1}$ jer pokazuje najveću promjenu vrijednosti transmisije o koncentraciji, a ima i najlinearniji odziv s $R^{2}=0,9998$.

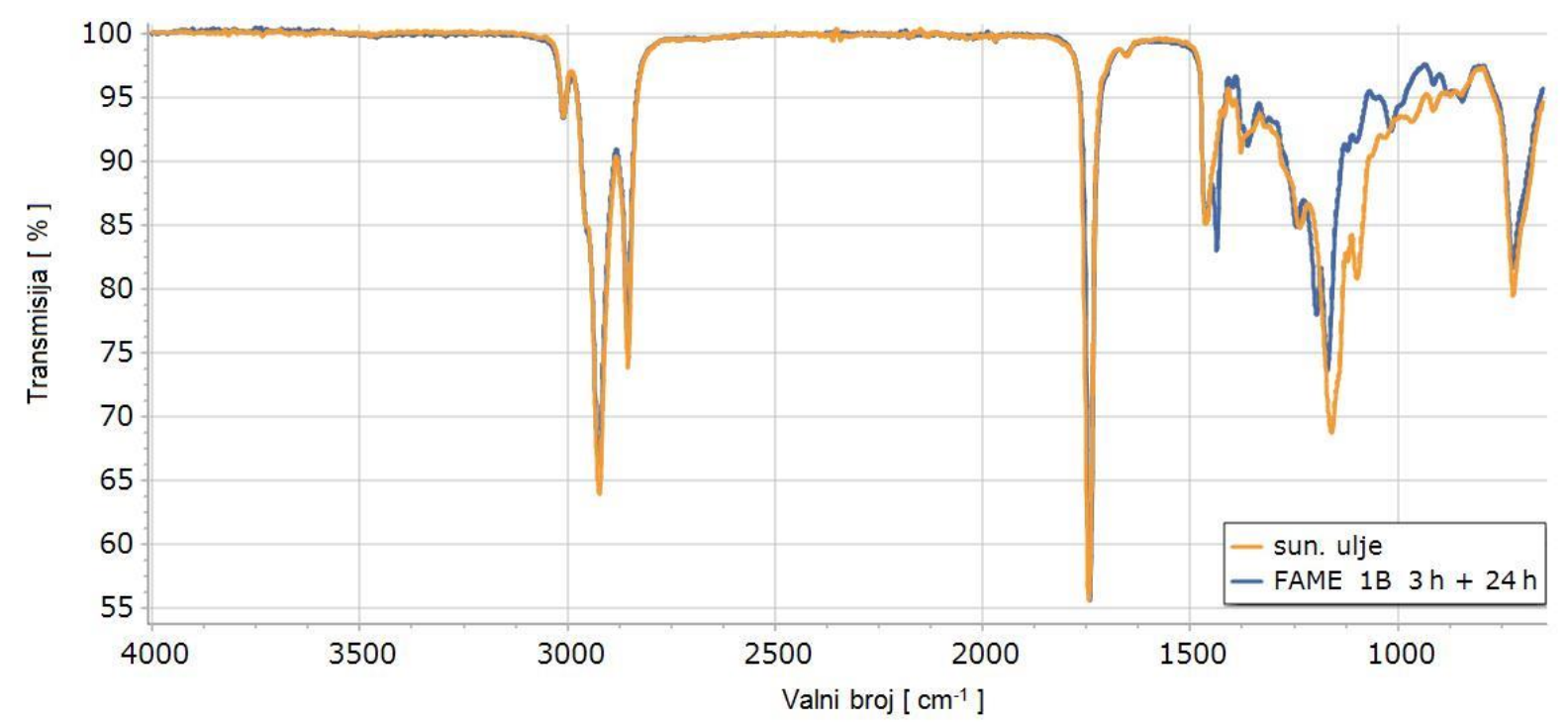

Slika 3 - FTIR spektri suncokretova ulja i FAME dobiveni reakcijom u kotlastom reaktoru

(3 h reakcije $+24 \mathrm{~h}$ na sobnoj temperaturi)

Fig. 3 - FTIR spectra of FAME and sunflower oil obtained by reaction in batch reactor 


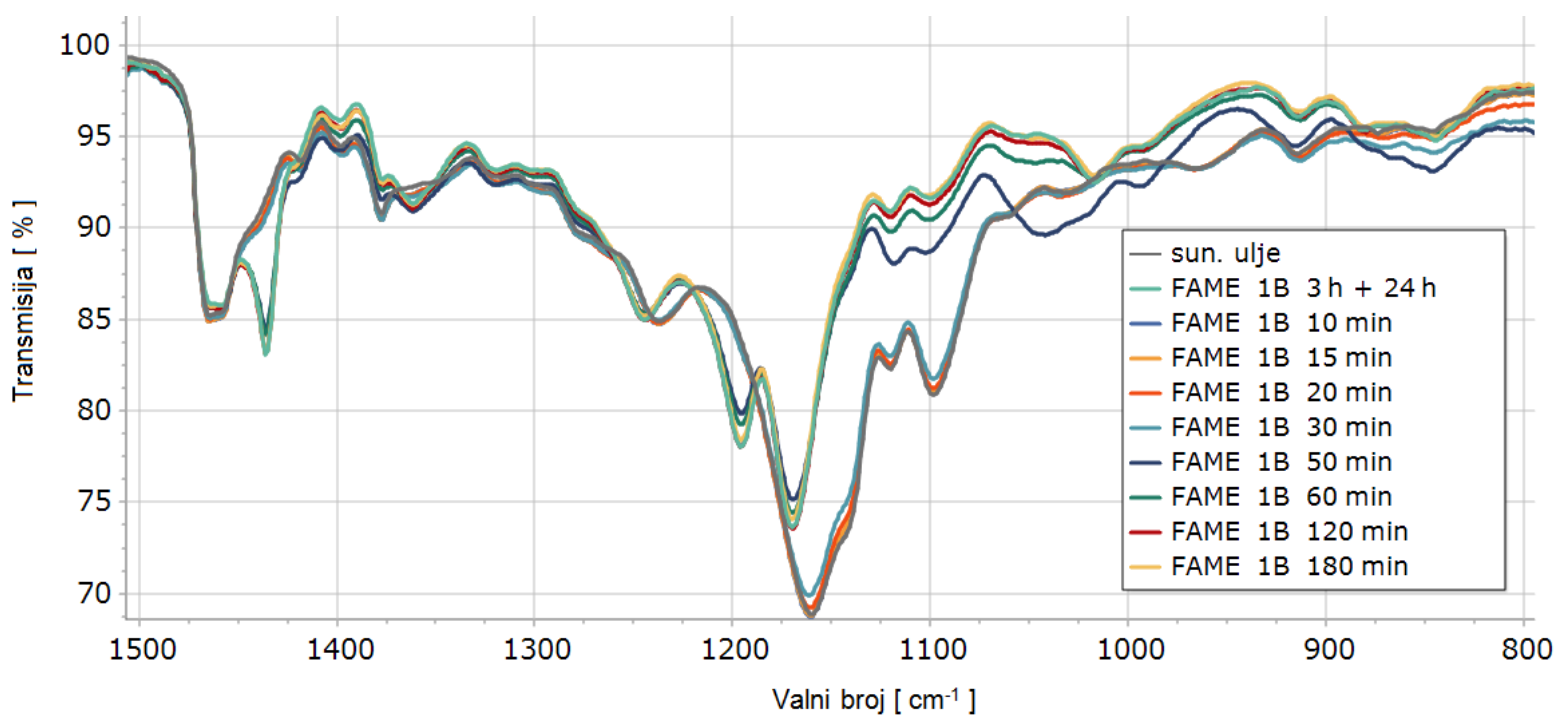

Slika 4 - Dio FTIR spektra sun. ulja i FAME dobivenih reakcijom u kotlastom reaktoru pri različitim vremenima uzorkovanja Fig. 4 - Part of FTIR spectrum of FAME and sunflower oil obtained by reaction in batch reactor at different sampling times

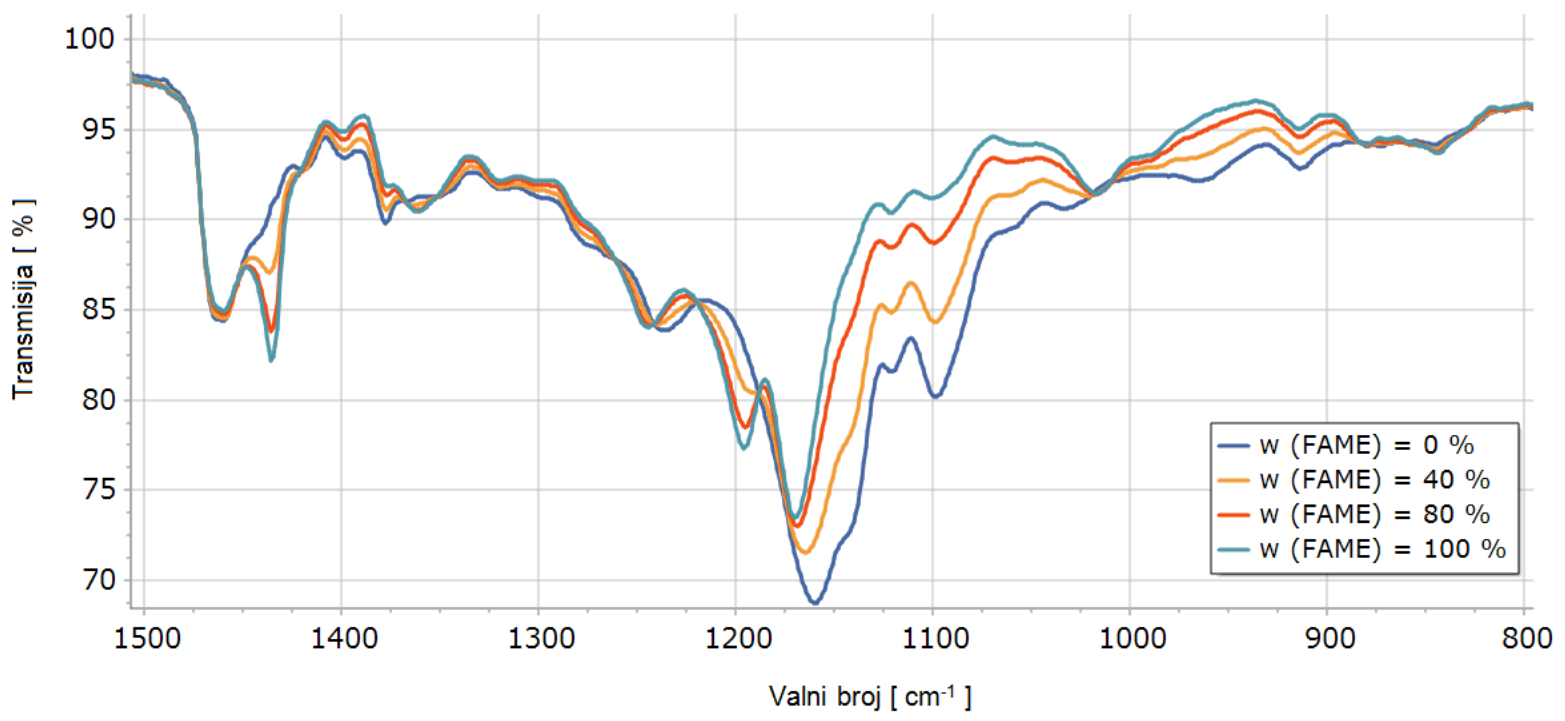

Slika 5 - Dio FTIR spektra baždarnih smjesa različitih koncentracija FAME za određivanje udjela FAME

Fig. 5 - Part of the FTIR spectrum of calibration mixtures of different FAME concentrations for determination of FAME content

\subsection{Reakcija u reaktorima s pregradama}

$U$ tablici 2 su navedena su četiri reaktora napravljena aditivnom proizvodnjom i njihove karakteristike - promjer kanala, promjer unutarnje pregrade valjkastog oblika, polimeri od kojih su izrađeni i duljina kanala. U tablici 3 navedeni su protoci i vremena zadržavanja pri kojima se provodila sinteza FAME. Usporedbom FTIR spektara čistog suncokretova ulja (slika 4), pripremljenih baždarnih smjesa (slika 5) i sintezom pripremljenih uzoraka, najveću konverziju pokazuju reaktori izrađeni tehnologijom SLA (RSP-120-SLA i RSP-370-SLA). Dobivena je $100 \%$-tna konverzija u reaktoru RSP-120-SLA (slika 7) pri vremenu zadržavanja, $\tau$, 4,6 min (tablica 3). U reaktoru RSP-370SLA usporedbom spektara ustanovljena je $100 \%$-tna konverzija pri vremenu zadržavanja 7,1 min (tablica 3, slika 8). Ostali protoci u navedenom reaktoru nisu istraživani. 
a)

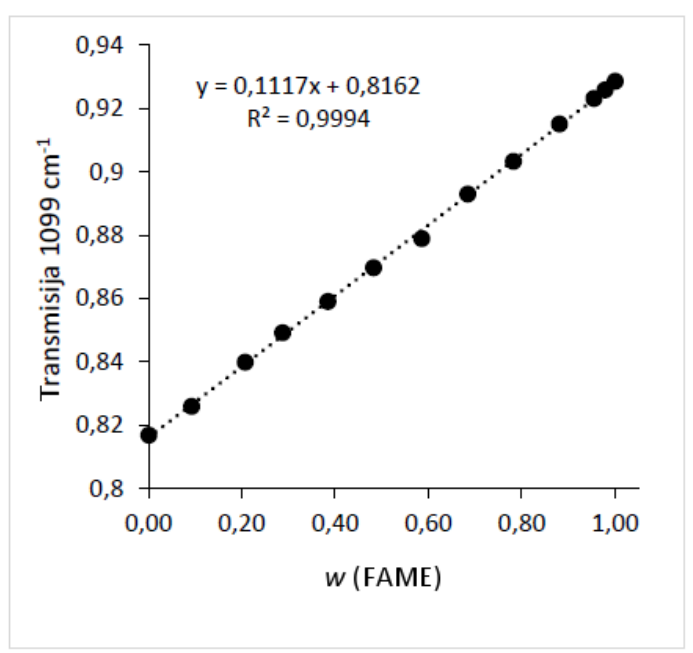

b)

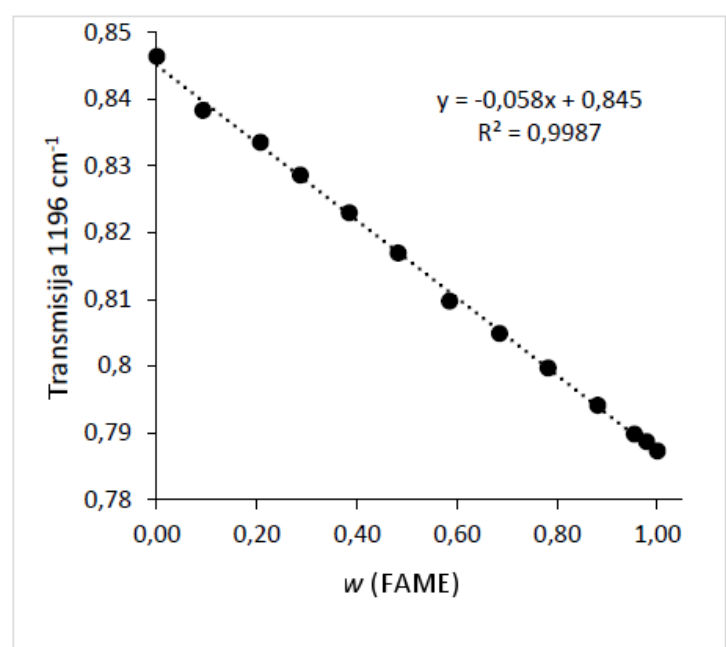

c)

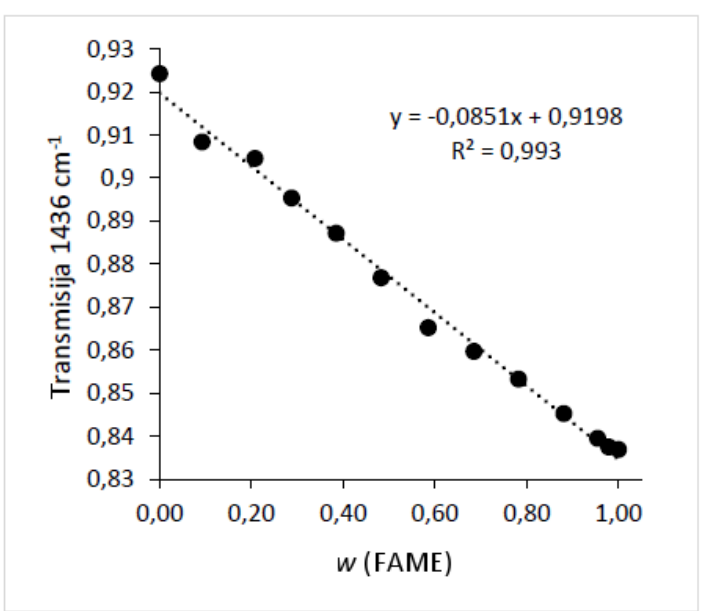

Slika 6 - Baždarni dijagrami ovisnosti transmisije o udjelu FAME za vrpce s vrhovima na $1436 \mathrm{~cm}^{-1}, 1196 \mathrm{~cm}^{-1}$ i $1099 \mathrm{~cm}^{-1}$ Fig. 6 - Calibration curves of transmittance vs FAME content, peaks at $1436 \mathrm{~cm}^{-1}, 1196 \mathrm{~cm}^{-1}$ and $1099 \mathrm{~cm}^{-1}$

Tablica 2 - Reaktori izrađeni aditivnom tehnologijom i njihove karakteristike Table 2 - Reactors made by additive manufacturing and their characteristics

\begin{tabular}{l|c|c|c|c}
\hline $\begin{array}{l}\text { Reaktori s } \\
\text { pregradama (RSP) }\end{array}$ & $\begin{array}{c}\text { Promjer } \\
\text { kanala }\end{array}$ & $\begin{array}{c}\text { Promjer unutarnje } \\
\text { pregrade }\end{array}$ & Polimer & Duljina kanala \\
\hline RSP-120-SLA & $2,5 \mathrm{~mm}$ & $1,2 \mathrm{~mm}$ & PA & $120 \mathrm{~mm}$ \\
RSP-370-SLA & $2,5 \mathrm{~mm}$ & $1,2 \mathrm{~mm}$ & PA & $370 \mathrm{~mm}$ \\
RSP-120-FFF & $2,5 \mathrm{~mm}$ & $1,2 \mathrm{~mm}$ & PMMA & $120 \mathrm{~mm}$ \\
RSP-520-FFF & $1,2 \mathrm{~mm}$ & $0,6 \mathrm{~mm}$ & ABS & $520 \mathrm{~mm}$ \\
\hline
\end{tabular}


Tablica 3 - Vremena zadržavanja i protoci u reaktorima upotrijebljenim za sintezu FAME Table 3 - Residence times and flow rates in reactors used for FAME synthesis

\begin{tabular}{|c|c|c|c|}
\hline & Vrijeme zadržavanja, $\tau / \min$ & $\begin{array}{l}\text { Protok metanol, } \\
Q_{\mathrm{MeOH}} / \mu l \min ^{-1}\end{array}$ & $\begin{array}{l}\text { Protok sun. ulje, } \\
Q_{\text {sun.ulje }} / \mu \mathrm{min}^{-1}\end{array}$ \\
\hline \multirow{4}{*}{ RSP-120-SLA } & 4,6 & 25 & 100 \\
\hline & 2,3 & 50 & 200 \\
\hline & 1,2 & 100 & 400 \\
\hline & 0,6 & 200 & 800 \\
\hline \multirow[t]{2}{*}{ RSP-370-SLA } & 7,1 & 50 & 200 \\
\hline & 4,6 & 25 & 100 \\
\hline \multirow{3}{*}{ RSP-120-FFF } & 2,3 & 50 & 200 \\
\hline & 1,2 & 100 & 400 \\
\hline & 0,3 & 400 & 1600 \\
\hline \multirow{3}{*}{ RSP-520-FFF } & 4,6 & 25 & 100 \\
\hline & 0,5 & 250 & 1000 \\
\hline & 0,2 & 500 & 2000 \\
\hline
\end{tabular}

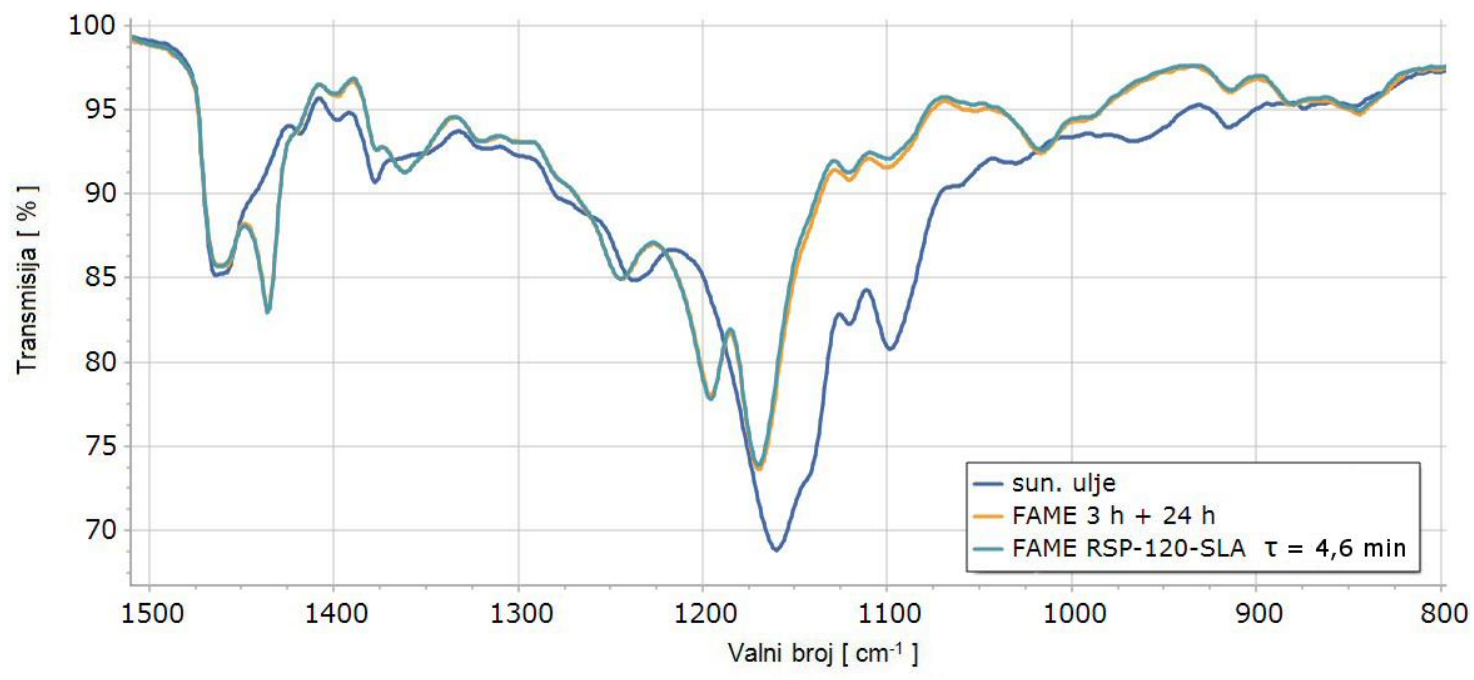

Slika 7 - Dio FTIR spektra FAME dobivenog u milireaktoru s pregradama RSP-120-SLA pri vremenu zadržavanja 4,6 min Fig. 7 - Part of the FTIR spectrum of FAME synthesized in millireactor with baffles RSP-120-SLA at residence time 4.6 min 


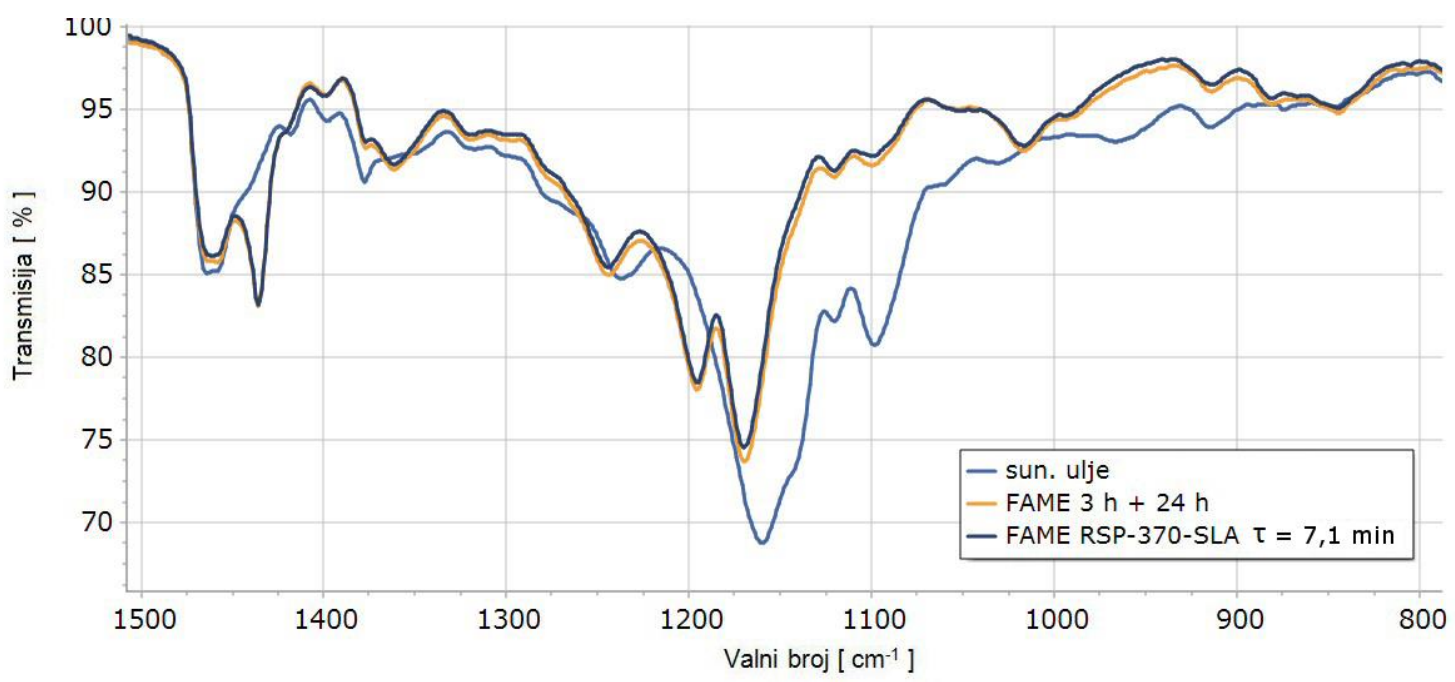

Slika 8 - Dio FTIR spektra FAME dobivenog u milireaktoru s pregradama RSP-370-SLA pri vremenu zadržavanja 7,1 min Fig. 8 - Part of the FTIR spectrum of FAME synthesized in millireactor with baffles RSP-370-SLA at residence time 7.1 min

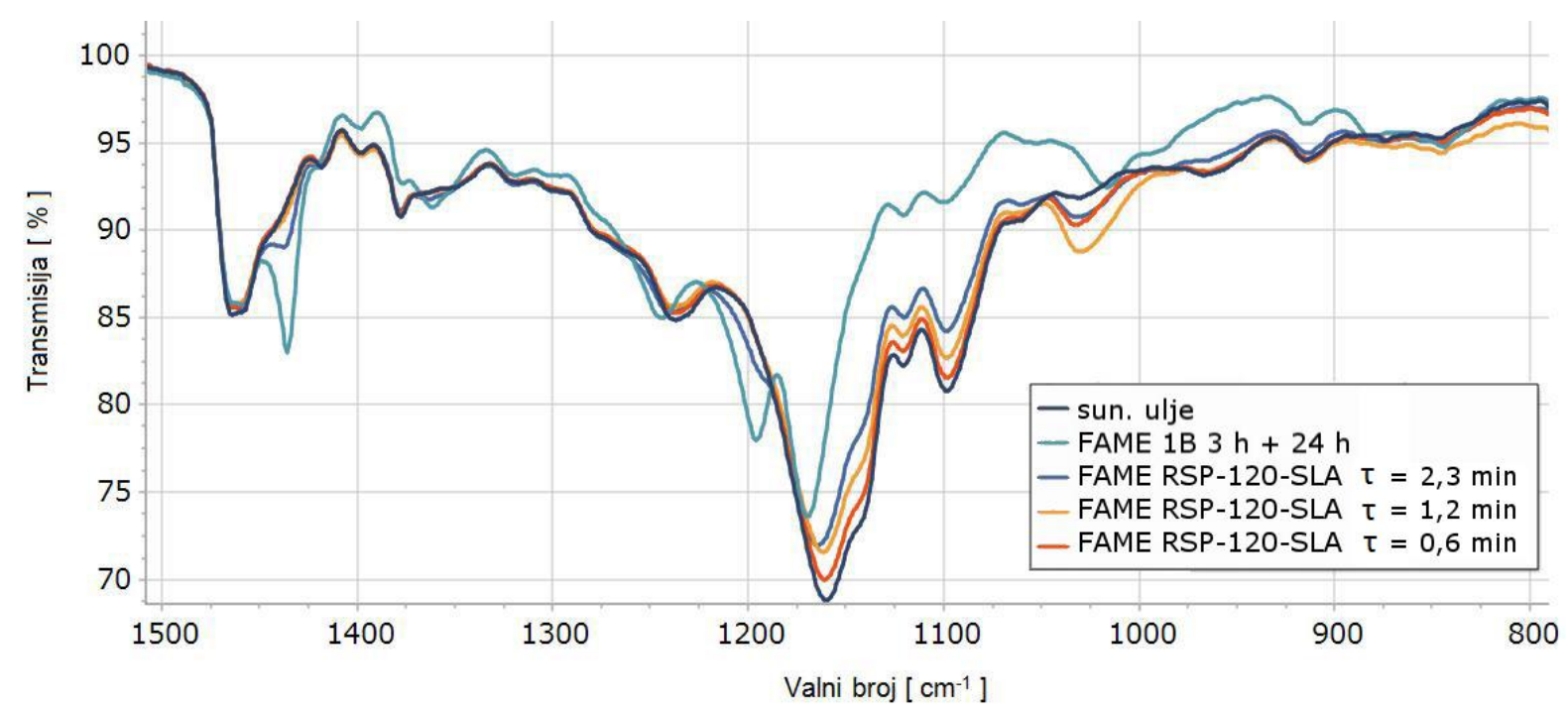

Slika 9 - Dio FTIR spektra FAME dobivenog u milireaktoru RSP-120-SLA, pri različitim vremenima zadržavanja

Fig. 9 - Part of the FTIR spectrum of FAME synthesized in millireactor with baffles RSP-120-SLA at different residence times 


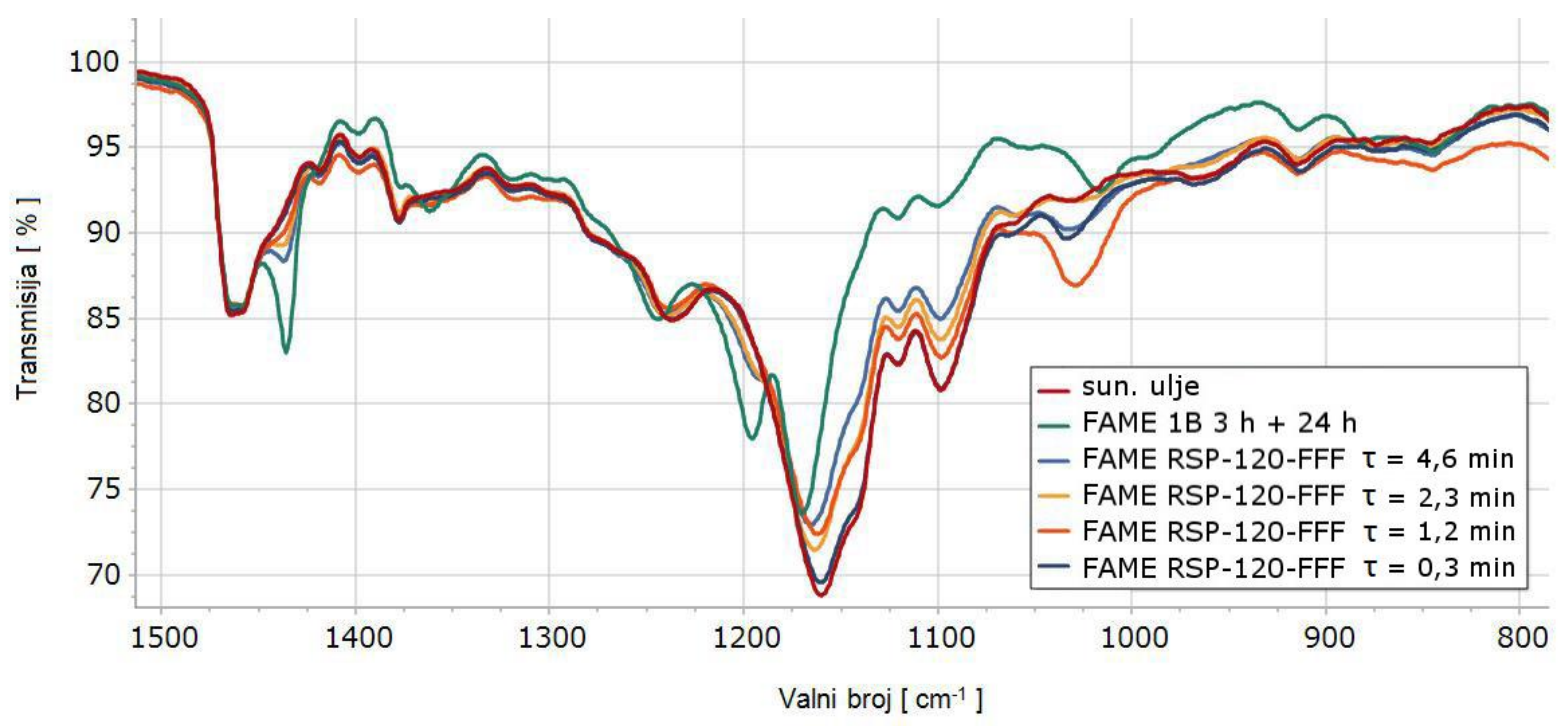

Slika 10 - Dio FTIR spektra FAME dobivenog u milireaktoru s pregradama RSP-120-FFF pri različitim vremenima zadržavanja Fig. 10 - Part of the FTIR spectrum of FAME synthesized in millireactor with baffles RSP-120-FFF at different residence times

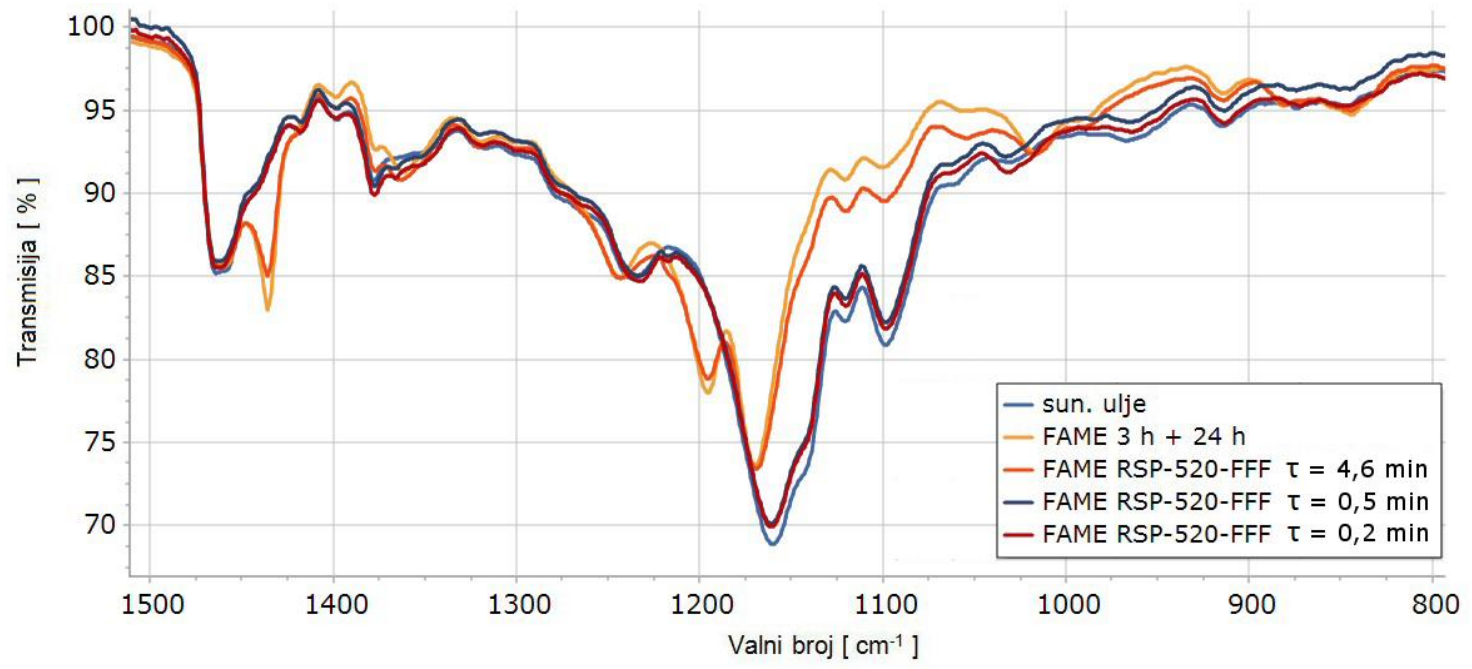

Slika 11 - Dio FTIR spektra FAME dobivenog u milireaktoru s pregradama (RSP-520-FFF) pri različitim vremenima zadržavanja

Fig. 11 - Part of the FTIR spectrum of FAME synthesized in millireactor with baffles (RSP-520-FFF) at different residence times

Pri većim protocima $\left(50 \mu \mathrm{min}^{-1} \mathrm{MeOH}+\right.$ kat. i $200 \mu \mathrm{min}^{-1}$ sun. ulja) u RSP-120-SLA postignuta je $40 \%$ tna konverzija FAME, $\tau=2,3$ min (tablica 3, slika 9). Niža konverzija se može pripisati kraćem vremenu zadržavanja jer je reaktor RSP-120-SLA manjeg volumena od RSP-370SLA u kojemu je pri navedenom protoku konverzija $100 \%$. U reaktoru RSP-120-FFF napravljenom od PMMA FTIR spektri (slika 10) pokazuju niže konverzije (40\% pri vremenu zadržavanja 4,6 min) u odnosu na isti model reaktora izrađenog SLA tehnologijom (RSP-120-SLA).
Potrebno je provesti daljnja istraživanja kako bi se navedeno objasnilo, moguće je da nije došlo do uspostavljanja stacionarnih uvjeta, ili da volumen izrađenog reaktora ne odgovara volumenu zadanom projektom, što nije bilo moguće vizualno odrediti jer reaktor izrađen od PMMA nije transparentan.

Milireaktor izrađen FFF tehnologijom (RSP-520-FFF) od polimernog materijala na osnovi ABS-a (Z-ULTRAT) ne zadovoljava uvjete vizualne kontrole, ali usporedbom 
spektara je u njemu postignuta $80 \%$-tna konverzija pri vremenu zadržavanja 4,6 min (slika 11). Pri ostalim vremenima zadržavanja, odnosno bržim protocima, nije došlo do transesterfikacije.

\section{Zaključak}

Uspješno su aditivnom proizvodnjom tehnologijama proizvodnje rastaljenim filamentom (FFF) i stereolitografije (SLA) proizvedeni cijevni reaktori $s$ pregradama. Provedena je sinteza FAME u tri reaktora istih promjera kanala $(2,5 \mathrm{~mm})$ i unutarnje pregrade valjkastog oblika $(1 \mathrm{~mm}) \mathrm{i}$ jednog s manjim promjerom kanala $(1,2 \mathrm{~mm})$, ali različite duljine, a time $i$ vremena zadržavanja. Usporedbom FTIR spektara čistog suncokretova ulja, pripremljenih baždarnih smjesa i sintezom pripremljenih uzoraka, određene su $100 \%$-tne konverzije u milireaktorima s pregradama RSP-120-SLA ( $\tau=4,6 \mathrm{~min}$ ) te RSP-370-SLA ( $\tau=7,1 \mathrm{~min}$ ). Također, navedeni reaktori zadovoljili su uvjete vizualne kontrole (prozirni su), dok je reaktor napravljen FFF tehnologijom od polimernog materijala na osnovi PMMA neproziran, te se ne može objasniti zašto su slabije konverzije (oko $40 \%$ pri $\tau=4,6 \mathrm{~min}$ ). Pretpostavka je da zbog hidrofobnosti upotrjebljenog polimernog materijala dolazi do odstupanja u strujanju reakcijske smjese kroz stjenke te da nije uspostavljeno stacionarno stanje. Za cjelovitu analizu rezultata potrebno je predložiti matematički model procesa koji bi u sebi sadržao fizičku sliku milireaktora s pregradama kao i kinetiku reakcije.

Napravljen je i milireaktor s pregradama (FFF tehnologijom) promjera kanala 1,2 $\mathrm{mm}$ i unutarnje pregrade valjkastog oblika $(0,6 \mathrm{~mm})$, u njemu je FAME dobiven samo pri vremenu zadržavanja $\tau=4,6$ min kada konverzija iznosi $80 \%$.

\section{ZAHVALA}

Ovaj je rad financirala Hrvatska zaklada za znanost projektom UIP-2014-09-3154.

\section{Popis kratica i simbola List of abbreviations and symbols \\ ABS - akrilonitril/butadien/stiren \\ - Acrylonitrile/butadiene/styrene \\ AM - aditivna proizvodnja \\ - Additive Manufacturing \\ FAEE - etilni esteri masnih kiselina \\ - Fatty Acid Ethyl Esters \\ FAME - metilni esteri masnih kiselina \\ - Fatty Acid Methyl Esters \\ FFF - proizvodnja rastaljenim polimerom \\ - Fused Filament Fabrication}

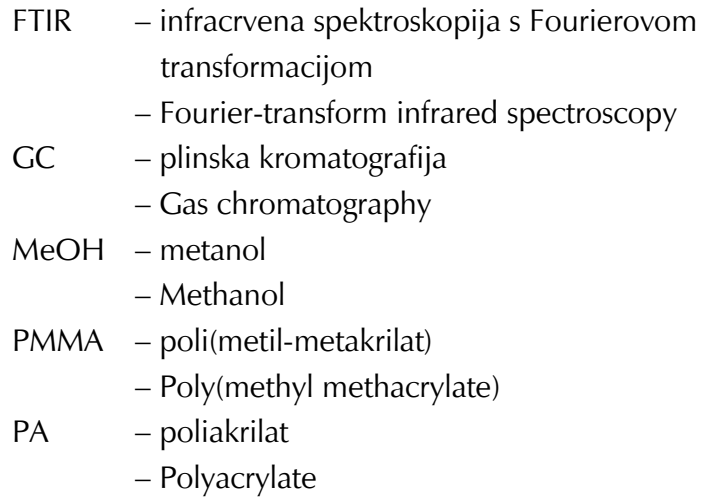

RSP-120-FFF - milireaktor s pregradama duljine kanala $120 \mathrm{~mm}$ izrađen FFF tehnologijom

- millireactor with baffles tube length $120 \mathrm{~mm}$ produced by FFF

RSP-520-FFF - mikroreaktor s pregradama duljine kanala $520 \mathrm{~mm}$ izrađen FFF tehnologijom

- microreactor with baffles tube length $520 \mathrm{~mm}$ produced by FFF

RSP-120-SLA - milireaktor s pregradama duljine kanala $120 \mathrm{~mm}$ izrađen SLA tehnologijom

- millireactor with baffles tube length $120 \mathrm{~mm}$ produced by SLA

RSP-370-SLA - milireaktor s pregradama duljine cijevi $370 \mathrm{~mm}$ izrađen SLA tehnologijom

- millireactor with baffles tube length $370 \mathrm{~mm}$ produced by SLA

SLA - stereolitografija

- Stereolithography

STL $\quad-$ STL format

- Standard Tessellation Language

sun. ulje - suncokretovo ulje

- Sunflower oil

Z-ULTRAT - polimerni materijal na osnovi ABS-a upotrijebljen za FFF

- ABS-based filament used for FFF

\section{Literatura}

References

1. K. Cooper, Rapid Prototyping Technology, Marcel Dekker, Inc., New York, 2003.

2. D. Godec, M. Šercer, Aditivne tehnologije - 4. industrijska revolucija?, Glasnik Akademije tehničkih znanosti Hrvatske, 19 (1) (2015) 1-3.

3. W. Ehrfeld, V. Hessel, H. Lowe, Microreactors: New technology for modern chemistry, Wiley-VCH, 2000., str. 1.

4. J. C. McDonald, D. C. Duffy, J. R. Anderson, D. T. Chiu, H. Wu, O. J. A. Schueller, G. M. Whitesides, Fabrication of microfluidic systems in poli(dimethylsiloxane), Electrophoresis $21 \quad$ (2000) 27-40, doi: https://doi.org/10.1002/(SICl)15222683(20000101)21:1<27::AID-ELPS27>3.0.CO;2-C. 
5. G. Knothe, J. V. Gerpen, Biodiesel Production, The Biodiesel Handbook, AOCS Press, 2005., doi: https://doi.org/10.1201/9781439822357.

6. S. I. Yeh, Y. C. Huang, C. Cheng, C. M. Cheng, J. T. Yang, Development of a millimetrically scaled biodiesel transesterification device that relies on droplet-based co-axial fluidics, Scient. Report. 6 (2016) 1-7, doi: https://doi.org/10.1038/s41598-016-0001-8.

7. N. G. Siatis, A. C. Kimbaris, C. S. Pappas, P. A. Tarantilis, M. G. Polissiou, Improvement of biodiesel production based on the application of ultrasound: monitoring of the procedure by FTIR spectroscopy, J. Am. Oil. Chem. Soc. 83 (2006) 53-57, doi: https://doi.org/10.1007/s11746-006-1175-1.

8. J. Hernando, P. Leton, M. P. Matia, J. L. Novella, J. AlvarezBuilla, Biodiesel and FAME synthesis assisted by microwaves: homogeneous batch and flow processes, Fuel 86 (2007) 1641-1644, doi: https://doi.org/10.1016/j.fuel.2006.11.003.

9. D. Wen, H. Jiang, K. Zhang, Supercritical fluids technology for clean biofuel production, Prog. Nat. Sci. 19 (2009) 273-284, doi: https://doi.org/10.1016/j.pnsc.2008.09.001.

10. Z. Wen, X. Yu, S.T. Tu, J. Yan, E. Dahlquist, Intensification of biodiesel synthesis using zigzag micro-channel reactors, Bioresource Technol. 12 (2009) 3054-3060, doi: https://doi.org/10.1016/j.biortech.2009.01.022.
11. G. Guan, K. Kusakabe, N. Sakurai, K. Moriyama, Continuous production of biodiesel using a microtube reactor, Chem. Eng. Trans. 14 (2008) 237-244.

12. S. O'Donnell, I. Demshemino, M. Yahaya, I. Nwadike, L. Okoro, A review on the spectroscopic analyses of biodiesel, Europ. Int. J. Sci. Technol. 2 (2013) 137-146.

13. N. M. Mahamuni, Y. Adewuyi, Fourier transform infrared spectroscopy (FTIR) method to monitor soy biodiesel and soybean oil in transesterification reactions, petrodiesel-biodiesel blends, and blend adulteration with soy oil, Energy Fuels 23 (2009) 3773-3782, doi: https://doi.org/10.1021/ef900130m.

14. T. Yuan, E. Akochi-Koble, D. Pinchuk, F. van de Voort, FTIR on-line monitoring of biodiesel transesterification, Int. J. Renew. Energy Biofuel. 2014 (2014) 1-13, doi: https://doi.org/10.5171/2014.178474.

15. A. Sánchez, R. Maceiras, A. Cancela, M. Rodríguez, Influence of $n$-hexane on in situ transesterification of marine macroalgae, Energies 5 (2012) 243-257, doi: https://doi.org/10.3390/en5020243.

16. URL: https://www.arduino.cc/ (10. 2. 2018.).

17. J. Yoshida, A. Nagaki, T. Iwasaki, S. Suga, Enhancement of chemical selectivity by microreactors, Chem. Eng. Technol. 28 (2005) 259-266, doi: https://doi.org/10.1002/ceat.200407127.

\section{SUMMARY}

\section{Milliflow Reactors Produced by Additive Manufacturing \\ Marija Lukić, Tin Rahelić, and Domagoj Vrsaljko}

Additive manufacturing enables production of prototypes and products with complex geometries, which cannot be created using regular manufacturing processes like turning and milling. With FFF (Fused Filament Fabrication) and SLA (Stereolithography), it is possible to produce internal structures, light gage pipes (millichannels), and parts within the parts (baffles). The aim of this research was to explore the possibilities of 3D printing on Zortrax M200 (FFF) and Formlabs Form 2 (SLA) devices for production of functional millireactors with internal baffles.

In order to investigate the influence of millichannels on the chemical reaction, but also demonstrate the functionality of the whole system, fatty acid methyl esters (FAME) were synthesized by transesterification of sunflower oil using methanol with the addition of base catalyst $\mathrm{KOH}$.

\section{Keywords}

Millireactor with internal baffles, additive manufacturing, 3D printing, fused filament fabrication, stereolithography, synthesis of FAME

University of Zagreb

Faculty of Chemical Engineering and Technology

Marulićev trg 19, 10000 Zagreb, Croatia
Received April 17, 2018

Accepted June 28, 2018 